\title{
Uses and limitations in the demonstration of specific circulating immune complexes in patients with amoebiasis
}

\author{
V. K. VINAYAK, R. K. SHANDIL, V. BANSAL*, K. SINGH*, D. K. BHASIN* \\ and $U$. KAUR
}

Division of Experimental Parasitology and Parasitic Immunology, Department of Experimental Medicine and - Gastroenterology, Postgraduate Institute of Medical Education and Research, Chandigarh 160 012, India

\begin{abstract}
Summary. A micro-enzyme linked immunosorbent assay (micro-ELISA) has been evaluated as a diagnostic test to detect amoebic antigen in polyethylene glycol (PEG) precipitated circulating immune complexes (CIC) in sera from patients with amoebiasis. The immune complexes were captured on rabbit anti-amoebic IgGcoated wells of microtitration plates and the complexed antigen was detected by enzyme linked antihuman immunoglobulins. A titre of $>160$ for the immune complexes was considered to be of clinical significance. The immunoassay detected amoebic, antigen-specific CIC in $35(94.5 \%)$ of 37 patients with confirmed amoebic liver abscess. Twenty $(55.5 \%$ ) of 36 clinically suspected cases of amoebic liver abscess had amoebic antigen-specific CIC and responded favourably to anti-amoebic chemotherapy. Only two $(20 \%)$ of 10 cases of non-dysenteric symptomatic intestinal amoebic infection had amoebic antigen-specific CIC. One $(10 \%)$ of 10 patients with non-amoebic intestinal disorders also had amoebic antigen in CIC. However, none of 15 cases of non-amoebic hepatic disorders that included hydatid disease, metastatic adenocarcinoma, hepatocellular carcinoma, cholecystitis and choledocal cyst, 13 cases of rheumatoid arthritis and 25 apparently healthy subjects had amoebic antigen in CIC. The levels of the amoebic antigen-specific CIC did not correlate $(p>0.05)$ with either the number of abscess(es) or lobe(s) of the liver involved. However, the levels of antigen-specific CIC were higher $(p<0.01)$ in patients with a liver size of more than $5 \mathrm{~cm}$ below the right costal margin. Antigen-specific CIC levels tended to decline or disappear during 3-6 months following completion of therapy. In spite of the limitations for diagnosing symptomatic intestinal amoebic disease, the demonstration of specific CIC is recommended as an immuno-diagnostic procedure for patients with suspected amoebic liver abscess.
\end{abstract}

\section{Introduction}

Amoebiasis due to the enteroinvasive protozoan Entamoeba histolytica, is world-wide in its distribution and has a spectrum of clinical manifestations. There are estimated to be more than 480 million carriers of $E$. histolytica in the world and 36 million cases of disabling colitis or extra-intestinal disease leading to 40000 deaths each year (Walsh, 1986). Globally, amoebiasis ranks third amongst the parasitic causes of death behind only malaria and schistosomiasis (Walsh, 1986). The diagnosis of amoebiasis is confirmed by finding the parasite in clinical material. However, it is not always possible to demonstrate the parasite when the infection has

Received 12 Sep. 1989; accepted 6 Nov. 1989. spread to extra-intestinal sites. Conventionally, the immuno-diagnosis of amoebic infection has been based on the demonstration of circulating antibodies to $E$. histolytica although the presence of antibodies does not differentiate between present and past clinical or subclinical infection (Abioye $e t$ al., 1972; Juniper et al., 1972; Healy et al., 1974), and anti-amoebic antibodies are known to persist for years after the successful treatment of an amoebic liver abscess (Abioye $e t$ al., 1972; Healy $e t$ al., 1974; Vinayak, 1975). The level of anti-amoebic antibodies has limited or no correlation with the severity of infection (Vinayak, 1975; Bos and Van den Eijk, 1976; Thomas et al., 1981), and clearly the demonstration of circulating anti-amoebic antibodies has major limitations as a diagnostic test. 
Demonstration of the presence of antigen in clinical material has been shown to be effective in the diagnosis of active microbial infection (Houba et al., 1970; Shahin et al., 1974; Natali and Cioli, 1976; Ngu and Blackett, 1977), and, recently, amoebic antigen in circulating immune complexes (CIC) has been detected in the sera of patients with amoebiasis by a solid phase radio-immunoassay (Pillai and Mohimen, 1982; Mohimen et al., 1989) or enzyme linked immunosorbent assay (Vinayak et al., 1986; Gandhi et al., 1988). However, the sensitivity and specificity of the detection of amoebic antigen and its level in differentiating present from past infection, or its relation to the severity of disease, has not been clearly understood. The present study was designed to investigate the diagnostic usefulness and limitations of the detection of amoebic antigen-specific circulating immune complexes by micro-enzyme linked immunosorbent assay (micro-ELISA).

\section{Material and methods}

\section{Clinical samples}

Serum samples were collected from patients with confirmed amoebiasis, clinically suspected cases of amoebiasis, cases of non-amoebic hepatic disorders, idiopathic ulcerative colitis and irritable bowel syndrome, rheumatoid arthritis and apparently healthy (control) subjects. The criteria for the diagnosis of the categories were:

Confirmed amoebic liver abscess (37 patients). These patients had an enlarged tender liver and associated toxaemia, abscess demonstrated on ultrasound, and aspiration of the abscess yielded "anchovy sauce" pus which was either sterile on bacteriological examination or revealed E. histolytica trophozoites. They had antiamoebic antibody titres $>64$ as determined by the indirect haemagglutination technique, and there was clinical recovery after specific anti-amoebic treatment with metronidazole and emetine.

Clinically suspected amoebic liver abscess (36 patients). All of these patients had enlarged tender livers associated with systemic toxaemia; aspiration of pus could not be done in 20 patients and in another 16 patients bacteriological examination of pus was not performed. Seven patients had anti-amoebic antibody titres $<64$. All had good to moderate recovery after anti-amoebic treatment.

Non-amoebic liver disorders (15 patients). These included two patients with pyogenic liver abscess confirmed by bacteriological examination of pus, three with hydatid disease confirmed at laparotomy, five with metastatic adenocarcinoma of the liver confirmed by fine needle aspiration cytology (FNAC), three with hepatocellular carcinoma confirmed by FNAC, one with acute cholecystitis and one with a choledocal cyst confirmed at surgery; none of these patients had detectable anti-amoebic antibodies in their sera.

Symptomatic non-dysenteric intestinal amoebiasis (10 patients). These patients had indeterminate gastrointestinal symptoms such as vague abdominal pain; none had dysentery but examination of stool samples by the formol ether method of concentration revealed the presence of E. histolytica cysts.

Non-amoebic intestinal disorders (10 patients). Five cases were of idiopathic ulcerative colitis confirmed by sigmoidoscopy and histological changes in biopsies and five cases were of irritable bowel syndrome.

Rheumatoid arthritis (13 patients). These were confirmed cases of rheumatoid arthritis. None had a history suggestive of amoebiasis and examination of stool samples was negative for trophozoites or cysts of $E$. histolytica. None had anti-amoebic antibodies in serum samples.

Apparently healthy individuals ( 25 subjects). These were adults of 20-30 years, resident in India since birth; they had no symptoms and physical examinations suggested that they were healthy. Repeated stool examinations did not reveal trophozoites or cysts of $E$. histolytica. None had anti-amoebic antibodies in serum samples.

\section{Preparation of amoebic antigen and antiserum}

Amoebic antigen was prepared from axenic E. histolytica (HMI) grown in Trypticase Panmede Serum medium (TPS-I) (Vinayak et al., 1980). Briefly, trophozoites from a 48 -h culture were washed with $0.15 \mathrm{M}$ phosphatebuffered saline (PBS) pH 7.2 (sodium chloride $8.0 \mathrm{~g} / \mathrm{L}$, potassium chloride $0.20 \mathrm{~g} / \mathrm{L}$, disodium hydrogen phosphate $1.15 \mathrm{~g} / \mathrm{L}$, potassium dihydrogen phosphate 0.20 $\mathrm{g} / \mathrm{L}$ ), and disintegrated ultrasonically in ice at $23 \mathrm{Kc} / \mathrm{s}$ with 15 10-s bursts in an MSE ultrasonic disintegrator (Measuring and Scientific Equipment, UK). The sonicated material was centrifuged at $2000 \mathrm{~g}$ for $30 \mathrm{~min}$ at $4^{\circ} \mathrm{C}$ and the clear supernate was labelled as Crude Amoebic Extract (CAE). Antibodies to CAE were raised in rabbits by three subcutaneous injections, at 7-day intervals, containing $2 \mathrm{mg}$ of amoebic protein in Freund's complete adjuvant. The fourth dose containing $1 \mathrm{mg}$ of amoebic protein was given intravenously one week later. Ten days after the last dose, each rabbit was bled to death and the serum was separated. The immunoglobulin IgG fraction of anti-amoebic serum was prepared by DEAE cellulose chromatography (Hudson and Hay, 1980) and used as the solid phase (coating antibody) in a microELISA.

\section{Polyethylene glycol (PEG) precipitation of circulating immune complexes (CIC)}

CIC were prepared by precipitation of sera with PEG (mol. wt 6000; E. Merck) (Hudson and Hay, 1980). Briefly, $0.2 \mathrm{ml}$ of serum was mixed with PEG (final concentration $2.5 \%$ ) in veronal-buffered saline (VBS), pH 7.6 (sodium chloride $8.5 \mathrm{~g} / \mathrm{L}$, sodium barbitone $0.375 \mathrm{~g} / \mathrm{L}$, barbitone $0.575 \mathrm{~g} / \mathrm{L}$ in distilled water) contain- 
ing $0.01 \mathrm{M}$ ethylenediamine tetra-acetic acid. Finally, the precipitates were redissolved in $0.2 \mathrm{ml}$ of VBS, $\mathrm{pH} 7.6$, at $37^{\circ} \mathrm{C}$ for $1 \mathrm{~h}$ and used in the immunoassay.

\section{Micro-ELISA}

The optimal dilutions of coating anti-amoebic antibody (IgG) and precipitated immune complexes were determined by chess-board titration (Vinayak et al., 1986). Briefly, ELISA was performed by coating $100-\mu \mathrm{l}$ of optimally diluted rabbit anti-amoebic IgG on 96-well vinyl microtitration plates (Costar Corporation, USA) in $0.05 \mathrm{M}$ carbonate buffer, $\mathrm{pH} 9.6$ (sodium carbonate 1.59 $\mathrm{g} / \mathrm{L}$, sodium hydrogen carbonate $2.93 \mathrm{~g} / \mathrm{L}$ ) in distilled water. After incubation at $37^{\circ} \mathrm{C}$ for $3 \mathrm{~h}$, the plates were washed with $0.15 \mathrm{M}$ PBS, $\mathrm{pH} 7 \cdot 2$, containing Tween 20 $0.05 \%$ (PBS-T) and the non-specific reactions were blocked by adding $200 \mu \mathrm{l}$ of bovine serum albumin $0.5 \%$ in PBS-T. To each well was added $100 \mu$ l of serially diluted (80-10 240) CIC. After incubation for $3 \mathrm{~h}$ at $37^{\circ} \mathrm{C}$ for the antigen-antibody reaction, $100 \mu$ of a 1 in 4000 dilution of peroxidase conjugated antihuman (IgG + IgA + IgM) immunoglobulins (Dakopatts a/s, Denmark) was added and the reaction was developed by adding $100 \mu \mathrm{l}$ of orthonitrophenylene diamine $5 \mathrm{mg}$ in $10 \mathrm{ml}$ of $0.15 \mathrm{M}$ citrate phosphate buffer, $\mathrm{pH} 5.0$ (citric acid 21.0 $\mathrm{g} / \mathrm{L}$, disodium hydrogen orthophosphate $35.6 \mathrm{~g} / \mathrm{L}$ ) and $5 \mu \mathrm{l}$ of hydrogen peroxide. The reaction was terminated with sulphuric acid $12.5 \%$ and the results were read visually.

\section{Determination of cut-off titre for CIC}

A cut-off titre for the diagnostic significance of amoebic antigen in CIC was determined by comparing the CIC titres from 15 patients with confirmed amoebic liver abscess with those from 10 healthy control subjects.

\section{Follow up of patients}

Eight patients with confirmed amoebic liver abscess were followed with serial samples to investigate the decline of amoebic antigen-specific CIC after recovery. The blood samples were collected 1, 3 and 6 months or 3 years after the completion of therapy. At each follow up, a detailed clinical examination confirmed that all patients were normal and healthy.

\section{Results}

\section{Determination of cut-off titre}

Plotting the titres of amoebic antigen-specific CIC obtained from patients with confirmed amoebic liver abscesses and those from normal control subjects showed that patients with an amoebic liver abscess had CIC titres $>160$ whereas all the control subjects had titres of $\leqslant 160$ (figure). Therefore, a titre of $>160$ was considered significant for diagnostic purposes.

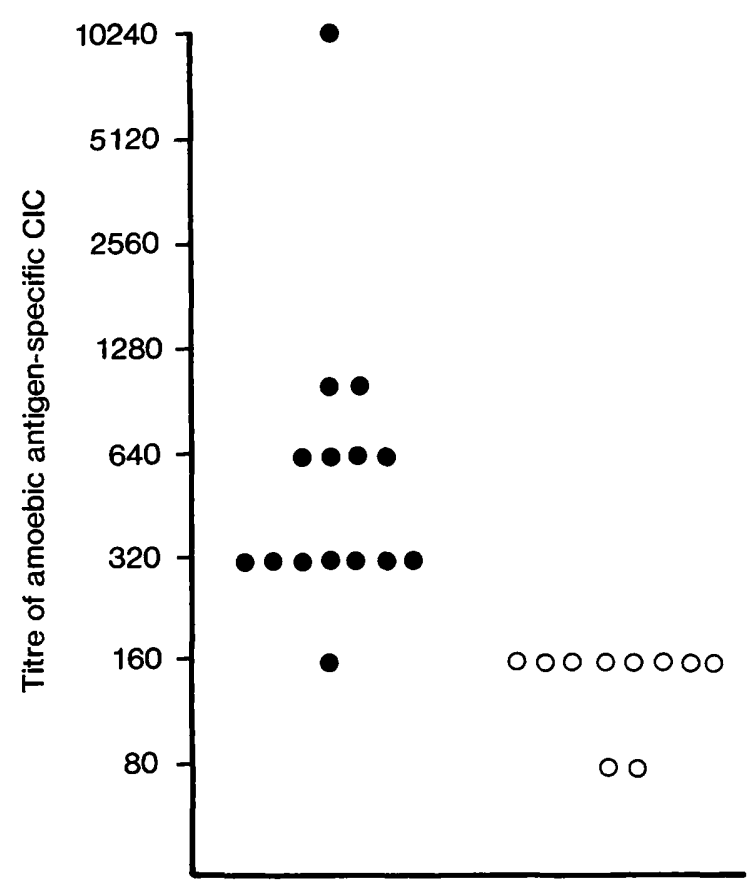

Figure. CIC titres in serum samples from patients with confirmed amoebic liver abscesses $(O)$ and healthy subjects $(O)$.

\section{Clinical evaluation of amoebic antigen-specific CIC by ELISA}

Thirty five $(94.5 \%)$ of the 37 patients with a confirmed amoebic liver abscess had amoebic antigen in CIC with a titre of $>160$, and $20(55.5 \%)$ of 36 patients with suspected amoebic liver abscess had amoebic antigen-specific CIC titres $>160$. All of the $20 \mathrm{CIC}$-positive patients with suspected amoebic abscesses responded favourably to antiamoebic therapy. None of the 15 patients with nonamoebic hepatic disorders (pyogenic abscess, hydatid cyst, metastatic adenocarcinoma, hepatocellular carcinoma, cholecystitis or choledocal cyst) or the 25 healthy subjects had detectable amoebic antigen-specific CIC. Furthermore, none of 13 patients with rheumatoid arthritis and only one $(10 \%)$ of 10 patients with non-amoebic intestinal diseases had amoebic antigen-specific CIC. Two $(20 \%)$ of the symptomatic non-dysenteric patients with intestinal amoebic infection had detectable levels of specific CIC (table I).

In 17 patients with confirmed amoebic liver abscess, an assessment of liver size and the number of abscesses in relation to levels of amoebic antigenspecific CIC indicated that the patients with a liver enlarged to $\leqslant 5 \mathrm{~cm}$ below the right costal margin tended to have amoebic antigen-specific CIC titres $\leqslant 640$ whereas patients with a liver enlarged to 
Table I. Anti-amoebic antibodies and amoebic antigen-specific CIC in different groups of patients

\begin{tabular}{lccc}
\hline \multicolumn{1}{c}{ Patient group } & $\begin{array}{c}\text { Number } \\
\text { tested }\end{array}$ & $\begin{array}{c}\text { Nor anti-amoebic anti- } \\
\text { body (titre }>64)\end{array}$ & $\begin{array}{c}\text { Number (\%) positive } \\
\text { for CIC (titre > 160) }\end{array}$ \\
\hline Confirmed amoebic liver abscess & 37 & $35(94 \cdot 5)$ & $35(94 \cdot 5)$ \\
Suspected amoebic liver abscess & 36 & $29(80 \cdot 5)$ & $20(55 \cdot 5)$ \\
Non-amoebic liver disorders & 15 & 0 & 0 \\
Symptomatic non-dysenteric in- & 10 & $2(20 \cdot 0)$ & $2(20 \cdot 0)$ \\
testinal amoebic infection & & & $1(10 \cdot 0)$ \\
Non-amoebic intestinal disorders & 10 & $1(10 \cdot 0)$ & 0 \\
Rheumatoid arthritis & 13 & 0 & 0 \\
Healthy subjects & 25 & 0 & \\
\hline
\end{tabular}

$5 \mathrm{~cm}$ below the right costal margin had significantly higher levels $(p<0.01)$ of amoebic antigen-specific CIC. There was no significant correlation $(\mathrm{p}>0.05)$ between the levels of amoebic antigen-specific CIC and the number or location of abscesses in the liver (table II). The titres of amoebic antigen-specific CIC at follow-up of eight patients with confirmed amoebic liver abscess declined or became zero within 1-6 months after the completion of antiamoebic therapy. One patient (no. 8) examined 3 years after the anti-amoebic therapy had no detectable levels of amoebic antigen-specific CIC and was clinically normal (table III).

\section{Discussion}

The presence of increased serum CIC in patients with amoebic liver abscess and in chronic cyst passers have been employed for the diagnosis of

Table II. Relationship between clinical findings and titres of amoebic antigen-specific CIC

\begin{tabular}{|c|c|c|c|c|}
\hline \multirow{2}{*}{$\begin{array}{c}\text { Feature of liver } \\
\text { disease }\end{array}$} & & \multicolumn{3}{|c|}{$\begin{array}{l}\text { Number of patients with amoe- } \\
\text { bic antigen-specific CIC titres }\end{array}$} \\
\hline & & $\leqslant 640$ & & $>640$ \\
\hline \multirow{5}{*}{$\begin{array}{l}\text { Liver size below } \\
\text { right costal margin } \\
\text { Number of } \\
\text { abscess(es) } \\
\text { Lobe(s) of the liver } \\
\text { involved }\end{array}$} & $\begin{array}{l}\leqslant 5 \mathrm{~cm} \\
>5 \mathrm{~cm}\end{array}$ & $\begin{array}{l}8 \\
0\end{array}$ & $\mathrm{p}<0.01^{*}$ & $\begin{array}{l}3 \\
6\end{array}$ \\
\hline & $\begin{array}{r}1 \\
>1\end{array}$ & $\begin{array}{l}4 \\
4\end{array}$ & $\mathrm{NS}^{*}$ & $\begin{array}{l}7 \\
2\end{array}$ \\
\hline & Right & 4 & \multirow{3}{*}{ NS* } & 7 \\
\hline & Left & 0 & & 1 \\
\hline & Both & 4 & & 1 \\
\hline
\end{tabular}

NS, differences not significant.

*Statistical analysis was by the $\chi^{2}$ test. amoebiasis (Nuti et al., 1982). Recent studies have indicated that the demonstration of amoebic antigen in CIC appears to be a reliable immunodiagnostic approach in amoebiasis (Vinayak et al., 1986; Gandhi et al., 1988; Mohimen et al., 1989). The data in the present report show that a CIC titre of $>160$ differentiated patients with active amoebic liver abscess from healthy subjects and those with non-amoebic hepatic disorders. The sensitivity of micro-ELISA for the demonstration of amoebic antigen-specific CIC in patients with confirmed liver abscess was found to be $94.5 \%$. In 20 (55.5\%) of 36 cases of clinically suspected amoebic liver abscess, amoebic antigen-specific CIC was detected. All of these 20 patients responded favourably to anti-amoebic therapy whereas the 16 clinically suspected cases who had no demonstrable amoebic antigen-specific CIC failed to respond to antiamoebic therapy. The results indicate that patients who are suspected clinically of having an amoebic

Table III. Amoebic antigen-specific CIC after treatment in eight patients with amoebic liver abscess

\begin{tabular}{|c|c|c|c|c|c|}
\hline \multirow{3}{*}{$\begin{array}{c}\text { Patient } \\
\text { no. }\end{array}$} & \multicolumn{5}{|c|}{ Titres of amoebic antigen-specific CIC } \\
\hline & \multirow{2}{*}{$\begin{array}{c}\text { Before } \\
\text { treatment }\end{array}$} & \multicolumn{4}{|c|}{ After treatment } \\
\hline & & 1 month & 3 months & 6 months & 3 years \\
\hline 1 & 320 & 160 & 160 & ND & ND \\
\hline 2 & 640 & 320 & 160 & ND & ND \\
\hline 3 & 320 & 320 & 160 & ND & ND \\
\hline 4 & 640 & 320 & 160 & ND & ND \\
\hline 5 & 640 & 320 & 160 & ND & ND \\
\hline 6 & 320 & 320 & 160 & 160 & ND \\
\hline 7 & 1280 & 1280 & 0 & 0 & ND \\
\hline 8 & 1280 & 1280 & ND & ND & 0 \\
\hline
\end{tabular}

ND, not done. 
liver abscess and who also have amoebic antigenspecific CIC in their circulation are cases of amoebic liver abscess and should be treated with appropriate anti-amoebic therapy. The specificity of amoebic antigen-specific CIC is clearly indicated; it was not detected in serum from patients with non-amoebic hepatic disorders, rheumatoid arthritis and from apparently healthy subjects. However, the use of CIC has a considerable limitation in the diagnosis of symptomatic non-dysenteric intestinal amoebiasis. The low rate of detection of amoebic antigen in symptomatic non-dysenteric intestinal cyst passers may be related to less tissue invasion in such patients, compared with the tissue invasion by the parasite in patients with amoebic liver abscesses. Moreover, the demonstration of specific amoebic antigen in cases of acute amoebic dysentery needs to be evaluated in depth. In contrast to the limited correlation of anti-amoebic antibody levels with

\section{REFERENCES}

Abioye A A, Lewis E A, McFarlane H 1972 Clinical evaluation of serum immunoglobulins in amoebiasis. Immunology 23: 937-946

Bos H J, Van den Eijk A A 1976 Enzyme linked immunosorbent assay (ELISA) in the serodiagnosis of amoebiasis In: Sepulveda S, Diamond L S (eds) Memorias de la Conferencia Internacional Sobre Amibiasis. Instituto Mexicano del Seguro Social, Mexico, pp 721-727.

Gandhi B M, Irshad M, Acharya S K, Tandon B N 1988 Amebic liver abscess and circulating immune complexes of Entamoeba histolytica proteins. American Journal of Tropical Medicine and Hygiene 39: 440-444.

Healy G R, Visvesvara G R, Kagan I G 1974 Observations on the persistence of antibodies of $E$. histolytica. Archives of Investigative Medicine (Mex) 5 (Suppl 2): 495-500.

Houba V, Allison A C, Hendrickse R G, de Petrics S, Edgington G M, Adeniyi A 1970 Immune complexes in the nephrotic syndrome of Nigerian children In: Bonomo L, Turk J L (eds) Immune complex disease. Carlo Erba Foundation, Milan, pp 23-28.

Hudson L, Hay F C 1980 Practical immunology, 2nd edn. Blackwell Scientific Publications, Oxford, p 226.

Juniper K, Worrel C L, Minshew M C, Roth L S, Cypert H, Lyoyd R E 1972 Serologic diagnosis of amebiasis. American Journal of Tropical Medicine and Hygiene 21 : 157-168.

Mohimen A, Maitra T K, Jalan K N, Mehra S 1989 A specific solid-phase assay for the detection of immune complexes containing Entamoeba histolytica antigens. Journal of Immunological Methods 117: 39-44.

Natali P G, Cioli D 1976 Immune complex nephritis in Schistosoma mansoni-infected mice. European Journal of Immunology $6: 359-364$. the severity of disease, the titres of amoebic antigenspecific CIC correlated with the size of the liver; those patients whose liver was enlarged to $>5 \mathrm{~cm}$ below the right costal margin had significantly higher CIC titres. Therefore, CIC titres may be useful in indicating the severity of disease processes in these patients. There was no correlation between the amoebic antigen-specific CIC titres and either number of abscesses or the lobe of the liver involved. The amoebic antigen-specific CIC titres either declined or fell to zero 1-6 months after therapy. This observation indicates that the demonstration of amoebic antigen-specific CIC could differentiate between active amoebic disease in the liver and past amoebic exposure. In spite of the limitations in diagnosing non-dysenteric intestinal amoebic infection, the demonstration of amoebic antigenspecific CIC is considered to be valuable in patients with amoebic liver abscess.

Ngu J L, Blackett K 1977 Complement and immunoconglutinin changes in the nephrotic syndrome of adult Africans. American Journal of Tropical Medicine and Hygiene 73: 250 254.

Nuti M, D'Amelio R, Seminara R, Palmisano L, Aiuti F 1982 Circulating immune complexes in amoebiasis. Transactions of the Royal Society of Tropical Medicine and Hygiene 76: 567-568.

Pillai S, Mohimen A 1982 A solid-phase sandwich radioimmunoassay for Entamoeba histolytica proteins and detection of circulating antigens in amoebiasis. Gastroenterology 83: 1210-1216.

Shahin B, Papadopoulou Z L, Jenis E H 1974 Congenital nephrotic syndrome associated with congenital toxoplasmosis. Journal of Pediatrics 85: 366-370.

Thomas V, Sinniah B, Leng Y P 1981 Assessment of the sensitivity, specificity and reproducibility in the indirect immunofluorescent technique for the diagnosis of amebiasis. American Journal of Tropical Medicine and Hygiene 30: $57-62$.

Vinayak V K 1975 The specificity of indirect haemagglutination test in the diagnosis of amoebiasis. Indian Journal of Preventive and Social Medicine 6: 271-276.

Vinayak V K, Jain P, Gupta B, Kaushik S P, Sawhney S 1980 Cellular and humoral responses in amoebic patients. Tropical and Geographical Medicine 32 : 298-302.

Vinayak V K, Purnima S, Singh K, Venkatwswarlu K, Nain C K, Mehta S K 1986 Specific circulating immune complexes in amoebic liver abscess. Journal of Clinical Microbiology 23: $1088-1090$.

Walsh J A 1986 Problems in recognition and diagnosis of amebiasis: Estimation of global magnitude of morbidity and mortality. Review of Infectious Diseases 8 : 228-238. 